\title{
THE CUSTOMER CONTENTMENT WITH PRODUCTS AND SERVICES IN TELECOMMUNICATIONS SECTOR IN THE SLOVAK REPUBLIC
}

Communication is very important for people. Means of communication are constantly increasing and new forms, and ways of communication are developing because of technological innovations. The paper is focused on a part of the marketing research of customers' contentment and their preferences in order to determine their requirements and preferences in the field of mobile and data services of mobile operators. Results and conclusions of this paper should help mobile operators to identify customers' needs and allow to customize their service offers. The level of competition in the selected market is relatively low, despite the fact that it is growing nowadays. The first part of the paper focuses on the theoretical basis of customer satisfaction in the telecommunications market and the second part on preferences survey and customers' contentment in the market and its evaluation results.

Keywords: Telecommunications, customer, market, hypothesis.

\section{Introduction}

In the time of globalisation, internalisation, social networks, information spreading and new ways of communication the ability to make up something new, creative, efficient and unique is a key factor of success [1].

The telecommunications sector is playing an increasingly important role in the development of economy and technological diffusion, and its infrastructure and new telematics services provide a fundamental underpinning for information economies. Service quality can be described as a rationale of differences between expectation and competence along the important quality dimensions. Parasuraman, Zeithaml and Berry identified ten requirements useful for customers' evaluation of the quality of services: reliability, responsiveness, tangibles, communication, credibility, security, competence, courtesy, understanding the customers and service accessibility [2].

Since the 1990s, the telecommunications sector has become a dynamic key area for the economic development of industrialised nations. This is the result of enormous technical progress as well as of the increased number of network operators and the intense competition that has developed. These factors, in turn, are a consequence of the removal of monopoly rights, which were mainly enjoyed by state-owned operators of public telecommunications networks [3]. It is well known that service quality, customer satisfaction and customer value are becoming the most important factors of business success for either manufacturers or service providers. However, many different conclusions have been reached and related studies are rather fragmented, especially with regard to customer value. Furthermore, there are few related studies with service quality, customer satisfaction and customer value and their influences on customers' future behaviours in the telecommunications industry [2]. The Slovak mobile communications market is still relatively young.

Several studies have been conducted with the intent to understand customer satisfaction or loyalty of mobile services customers [2, 3, 4, 5, 6, and 7], Most of these studies emphasize that customer loyalty and analysis of factors affecting it are important for the success of mobile services firms [8].

It has been well known that customer-perceived service quality, customer value and satisfaction have been the most important success factors of business competition for either manufacturers or service providers [7, 9, and 10].

Customer satisfaction generally means customer reaction to the state of fulfilment, and customer judgment of the fulfilled state [11]. It heightens customer loyalty and prevents customer churn, lowers customers' price sensitivity, reduces the costs of failed marketing and of new customer creation, reduces operating costs due to customer number increases, improves the effectiveness of

\footnotetext{
* Anna Krizanova, Gabriela Masarova, Juraj Kolencik

Department of Economics, Faculty of Operation and Economics of Transport and Communications, University of Zilina, Slovakia,

Email: gabriela.masarova@fpedas.uniza.sk
} 
advertising, and enhances business reputation [12]. The main factor determining customer satisfaction is the customers' own perception of service quality [13]. In earlier studies on mobile telecommunications services, service quality has been measured by call quality, pricing structure, mobile devices, value-added services, convenience in procedures, and customer support [14, 15 , and 16].

Telecommunications belong to the sector of notification techniques which provides systemic conditions for the implementation of public communications networks. These networks are used to transfer information between pairs or groups of participants in both directions in a dialog way. Telecommunications services provide transmission of information via telecommunications devices (computer, mobile phone, landline, etc.). The role of telecommunications is to process the signal (in the form of data or speech) and ensure its transmission from the transmitter to the receiver via metallic, optical or wireless lines. Telecommunications service providers may be just institutions and companies defined by law and respecting all legal requirements. Telecommunications belong to the sector of notification techniques which provides systemic conditions for the implementation of public communications networks.

\section{Characteristics of Slovak telecommunication market}

In 2012, according to the Statistical Office of the Slovak Republic the total revenues from own services and products in the telecommunications sector accounted for 2,126.1 million $€$. This amount is $0.62 \%$ decrease in sales compared to 2011 and $7.32 \%$ decrease compared to 2008 .

\subsection{Mobile operators and competition on the telecom- munications market}

Mobile operators with the largest market share on the Slovak telecommunications market in 2011 are:

- Slovak Telekom, Inc. (39\% market share),

- Orange Slovensko, Inc. (32\% market share),

- O2 Telefónica Slovakia, Ltd. (20\% market share),

- Others (9\% market share).

\subsection{Selected features of mobile operators market, key problems and survey aim}

The market potential is based on the number of residents who are or may potentially be mobile phone users. It is made up of - 5,114,774 inhabitants of the Slovak Republic. According to the Statistical Office of the Slovak Republic in 2011, the number of active SIM cards of mobile services was 5,983,059; it was 116.4
SIM cards on 100 inhabitantsThere are some features typical for the Slovak mobile operators market:

- low level of competition,

- high volume of sales, periodicity of businesses,

- strong market regulation,

- customers' sensitivity to price changes,

- lack of flexibility in the field of customers ' requirements.

The fast changes of the environment, economy, and technology etc. or globalization processes have impact on the needs and expectations that new companies must fulfil [14].

With regard to the market characteristics, specifications and current development related to the decrease in the market, it is necessary to obtain additional information regarding customer preferences. Because of the extensity of telecommunications market and wide spectrum of provided services, we decided to focus on the market of mobile operators and data services market. The survey aims to identify the requirements and preferences of customers and services provided to them. Marketing survey of customers' preferences on mobile and data telecommunications services market is realized due to lack of information of this kind, such as technical information and those from secondary sources.

Marketing survey of customers' preferences, focused on services provided by mobile operators, carried out on the market of mobile and data services within the Slovak republic.

Marketing research has the character of quantitative, single, descriptive survey pre-test

This survey helped to identify the requirements and preferences of customers for services provided by mobile operators in the selected market.

Survey realization is associated with the fact that there is a large number of customers and users of services provided by mobile operators in the market in Slovakia, evidenced by the statistics of the number of active SIM cards operators as well as a high degree of market saturation. Although the market capacity exceeds market potential, price of services provided by mobile operators are still relatively high. However, we believe that the use of these services despite this fact will not decrease significantly because it is a relatively popular form of communication among people. The low level of competition in the market has been caused by the strict regulatory actions of the Telecommunications Office of the Slovak Republic. This low level of competition in the selected market does not oblige providers of mobile telephony and data services to monitor and adapt their services to specific customer requirements. There is a slight liberalization in the market. This liberalization is particularly related to free regulatory measures, for example, the allowance of the telephone number transfer to another mobile operator. In recent years, there has been a slight increase in competition, decrease in market prices, reduction of interconnection fees for services and it was also linked to a slight decline in sales of mobile operators. Since the services 
do not still reflect the actual needs of customers, we think that just tracking customers' requirements and preferences of the provided services could lead to a competitive advantage and become a key factor for success in the market in the future.

The survey aim is based on the selected marketing problem. This aim leads to hypothesis determination and other survey process to reach the selected goal. The aim of this study is to find out the following information:

- information related to customers' requirements - mobile and data services - price, quality and quantity, safety, complexity, comfort, form of service provided, etc.,

- information about mutual relations and dependencies between the selected variables,

- information about preferences among the requirements of customers of mobile and data services,

- information regarding the respondents in demographic terms - gender, age, employment status, monthly income, level of education, place of residence.

For the needs of selected study we determined following hypotheses:

Hypothesis 1: The most preferred requirement of customers to mobile and data services in terms of activation time, price and form of provided services is the price.

Hypothesis 2: The most preferred form of communication is represented by voice talks regarding these factors: price, availability, reliability and user comfort.

Hypothesis 3: There is a relationship between the respondent's work position and daily use of mobile and data services.

\section{Methodology, data and variables}

The base set of respondents is made up of inhabitants of the Slovak republic at the age of 18 and over. The sample was determined by quota sampling based on demographic characteristics - age, place and gender. Through this method a quasi-representative sample of respondents was determined which can be considered representative only on a particular likelihood principle.

The sample size of respondents was determined by free available on-line calculator of the company Creative Research Systems engaged in marketing research, surveys and statistical data processing.

The above calculation indicates the need to address the questionnaire to 384 respondents. This sample was calculated at $95 \%$ confidence (accuracy) interval of estimate and margin of error in the estimate equal to 5. The margin of error reflects the width of the confidence interval which reflects the degree of particular parameter uncertainty. The survey was conducted by electronic questionnaire which was sent to 1000 respondents. The questionnaire included 15 questions. Initial questions focused on determining the age, gender and other demographic characteristics. Respondents in other issues determined the preferred service, communication method, ancillary services, etc

Data processing includes check and correction of erroneous data from the questionnaires, their classification into groups according to the answers of respondents, encoding and preparations for analysis. The correction consisted of discarding incorrectly, incompletely filled questionnaires and questionnaires with a large number of errors (if the numbers of incorrect and incomplete responses were greater than half of all responses). In the case of minor errors in individual questions some correction were made by re-contacting the respondent to amend or withdraw incorrect answers from the questionnaire.

Data classification into logical groups according to possible answers of respondents and selected demographic characteristics (age, gender, place of residence etc.) anticipate the data encryption. Data were processed, converted into electronic format and encrypted using software MS Excel and IBM SPSS Statistics 20. Encryption means the transformation of all possible answers of respondents into numerical values. Numerical values are an important step in preparing the data for analysis.

Data analysis was performed by computers. Statistical data, connection, interdependencies of variables were analysed and designed using the software MS Excel and IBM SPSS Statistics 20. The aim of data analysis is to draw conclusions and outcomes from the data collected in marketing research. Conclusions should contribute to the solution of defined marketing problem. When analysing the data, we base on the following statistical methods and procedures: descriptive and analytical statistics, semantic differential with3-level bipolar range, monotonic analysis of variance (MONANOVA, CONJOINT) etc.

To confirm or deny hypothesis 1 , we used CONJOINT analysis which is one of the most widely used quantitative methods in marketing survey. It allows to measure customer preferences for the selected combination of service parameters to ascertain how changes in these parameters affect purchasing behaviour and decision-making of customers. To confirm or deny hypothesis 2, i.e., the determination of respondents' most preferred form of communication, we used the method of semantic differential with the help of 3-level bipolar scale in the questionnaire.

This method is similar to rating scales and the process of its design works on the basis of opposites. The respondents select particular score on bipolar scale that best describes their attitude. The advantage of this method is an output in the form of transparent chart. This chart allows comparison of opinions and attitudes of respondents [17].

Pearson Chi - square test of independence tests the null hypothesis $\mathrm{H}_{0}$ which expresses the independence of variables. 
This method is part of a two-dimensional inductive statistics. If the $p$ - value is lower than the chosen significance level (traditionally $5 \%=0.05$ ), the null hypothesis is denied. Chosen significance level reflects the likelihood of an error if we deny the null hypothesis, which is in fact true. That is, if we find that the relationship between the selected variables exists, but, in fact, there is no relationship between them [18, 19 and 20].

When analysing the data obtained in a marketing survey, we used the processes of inductive statistics despite the fact that the quota sampling of respondents does not meet the prerequisites of randomness. It is possible to consider it as a representative selection only under a certain level of likelihood. The project duration was seven months.

\section{Outcomes and conclusions of customers' preferen- ces in the market of mobile and data services survey}

\section{H1:}

In the case of provided mobile and data services, following parameters related to customers' requirements were set:

- activation time,

- price and form of service providing.

We based on the assumption that all consumers want by purchasing services to maximize their usefulness. Respondents mostly perceived the change in price because the estimated benefits of the service at 51-75€ per month are the lowest. The result is that respondents prefer blanket price to prepaid cards in the terms of form of provided mobile and data services. According to the values of estimated usefulness, respondents prefer lower price of provided service to a higher one. We also found out that respondents prefer a faster activation of mobile and data services to a slower one.
In the next step of the analysis we estimated the importance of individual factors of provided mobile and data service. This allows us to determine the importance of individual criteria and the order of preferences of respondents for individual requirements while the estimated overall importance of each parameter is:

- form - 14.782,

- price - 61.149,

- activation time -24.069 .

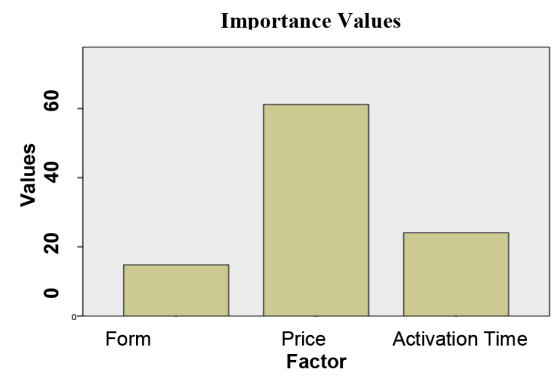

Fig. 1 Order of respondents' preferences according to importance Source: Self processed

The previous chart (Fig. 1) represents the order of preferences of the respondents in terms of the combination of their requirements on the price, form of the provided service and its activation. The most preferred parameter (requirement) is clearly the price followed by activation time of service and the last place is occupied by the form of service provided. Hypothesis 1 was confirmed.

H 2:

Table 1 shows average values of respondents' answers from the scale in questionnaire.

Comparison of individual ways of communication according to respondents

Table 1

\begin{tabular}{|l|c|c|c|c|c|}
\hline & Voice calls & SMS & MMS & Roaming & Data and internet communication \\
\hline Costingness & -0.800 & -0.240 & -1.240 & -1.580 & -0.560 \\
\hline Service reliability & 0.360 & 0.040 & -0.980 & -0.340 & -0.080 \\
\hline Service availability & -0.020 & 0.400 & -0.600 & 0 & -0.520 \\
\hline User comfort & -0.180 & -0.580 & -0.760 & -0.340 & -0.740 \\
\hline
\end{tabular}

Source: Self processed

\begin{tabular}{|l|c|}
\hline & Ideal form of communication \\
\hline Costingness & 2.990 \\
\hline Service reliability & 2.620 \\
\hline Service availability & 2.940 \\
\hline User comfort & 2.750 \\
\hline
\end{tabular}

Source: Self processed 
Ideal form of communication according to respondents based on selected criteria is mainly the low-cost communications (Table 2 ). Another important factor is the availability.

\section{Legend:}

Red line - voice communication

Black line - Roaming

Green line - Ideal communication

Dark blue line - SMS

Light blue line - MMS

Yellow line - Internet

\section{Semantic Differential Chart}

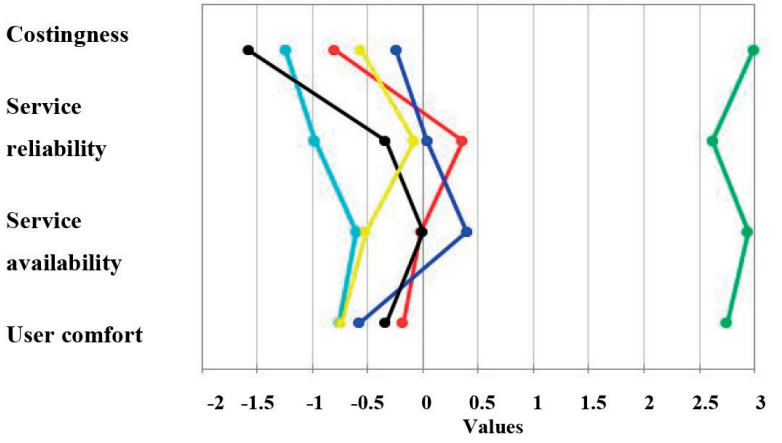

Fig. 2 Semantic differentials of selected communication forms and the ideal way

Source: Self processed

From the chart of semantic differential (Fig. 2) it is obvious that in term of the costingness, the SMS communication is closest to the ideal form of communication according to the answers of respondents. In terms of reliability the voice communication meets the ideal. In case of availability of services the SMS communication is best evaluated by respondents. Voice calls meet the ideal form of communication in terms of user comfort.

For accurate representation of the distances of selected real forms of communication from the ideal form we use D-statistics procedures. This method quantitatively compares the distance between ideal and real perceptions of respondents ' requests.

Results of D-statistics reflect the differences (distance) between the real and ideal perceptions of communication ways by respondents. The highest obtained value $\mathrm{D}$ means that the way of communication is most different from the ideal way (it has the greatest distance), while the lowest calculated value of $\mathrm{D}$ reflects the smallest difference between reality and ideal. The result of D-statistics is the SMS communication which represents the smallest difference between reality and ideal - 5.88. Based on calculated values we can consider SMS communication as the most ideal form according to respondents. Hypothesis 2 was denied.

\section{H 3:}

Null hypothesis $\left(\mathrm{H}_{0}\right)$ claims that there is no relationship between selected variables. On the other hand, hypothesis $\mathrm{H}_{1}$ declares the relationship existence between occupation of respondents and time of mobile and data services usage (Table 3).

Existence of relationship between selected variables

Table 3

\begin{tabular}{|l|c|c|c|}
\hline & Value & Df & Asymp. Sig. (2-sided) \\
\hline Pearson Chi-Square & $235.624 \mathrm{a}$ & 20 & .000 \\
\hline Likelihood Ratio & 250.707 & 20 & .000 \\
\hline Linear-by-Linear Association & 68.950 & 1 & .000 \\
\hline N of Valid Cases & 400 & & \\
\hline
\end{tabular}

Source: Self processed

Existence of independence between selected variables

Table 4

\begin{tabular}{|l|l|c|c|c|c|}
\hline & Value & Asymp. Std. Errora & Approx. Tb & Approx. Sig & \\
\hline \multirow{3}{*}{ Nominal by nominal } & Phi & .768 & & & .000 \\
\cline { 2 - 6 } & Cramer's V & .384 & & & .000 \\
\cline { 2 - 6 } & Contingency Coefficient & .609 & & & .000 \\
\hline \multirow{3}{*}{ Ordinal by Ordinal } & Kendall's tau-b & .402 & .027 & 13.441 & 0.000 \\
\cline { 2 - 6 } & Kendall's tau-c & .323 & .024 & 13.441 & 0.000 \\
\cline { 2 - 6 } & Spearman Correlation & .492 & .031 & 11.226 & $.000^{\circ}$ \\
\hline Interval by Interval & Pearson's R & .416 & .036 & 9.118 & $.000^{\circ}$ \\
\hline \multirow{2}{*}{$\mathrm{N}$ of Valid Cases } & & 400 & & & \\
\hline
\end{tabular}

Source: Self processed 
The resulting $\mathrm{p}$-value of the test is less than 0.05.This means that it is possible to deny the null hypothesis and confirm the existence of a relationship between occupations of the respondents and their daily time use of the services provided by mobile operators. Hypothesis 3 was confirmed.

We proved by the analysis that entrepreneurs and employees use daily more mobile services than unemployed, students and pensioners. In terms of frequency of the service usage, these segments are more attractive: entrepreneurs and employees (Table 4).

\section{Conclusion}

The survey result confirmed that customers in the Slovak market mostly prefer the price, then the service activation time and the form of provided service. Hypothesis 1 was confirmed. The customers' most preferred combination of selected requirements on mobile and data services is the service to $25 €$ per month, activated from 2 to 6 hours, and provided for blanket price. The preferences order for other combinations regarding the selected criteria cannot be created clearly. This fact was the objective of CONJOINT analysis where the order of respondents' preferences is sorted by: price, activation time, and the less preferred criteria - form of provided service.
Hypothesis 2 was denied. This results from the smallest distance between the ideal and the real form of communication according to these factors: costingness, availability, reliability and user comfort of the service. The SMS communication is followed by the second most ideal form - voice calls, then data, internet and roaming communication. The last place is, according to the distance between reality and ideal, occupied by the MMS communication.

Last hypothesis $\left(\mathrm{H}_{3}\right)$ was confirmed and there is an existence of a relationship between occupations of the respondents and their daily time use of the services provided by mobile operators. Evaluation of the above results leads us to the following conclusions: As we expected, the low level of competition in the Slovak market of mobile operators and service providers does not force towards improvement of services and lower prices. Customers' requirements are easily identifiable and, therefore, the businesses in this area should pay attention not only to massive advertising campaigns but also to satisfaction survey and customers' requirements.

\section{Acknowledgements}

The article is an output of scientific project VEGA 1/0473/12 Krizanova, A. et al.: Integrated model of building of brand value as a tool of business marketing mix.

\section{References}

[1] SOVIAR, J., VODAK, J.: Value Network as Part of New Trends in Communication, Communications - Scientific Letters of the University of Zilina, (2), 2012. ISSN: 1335-4205.

[2] WANG, Y. S., LIAO, Y. W.: The Conceptualization and Measurement of Commerce user Satisfaction. Computers in Human Behavior, 2(1), p. 381-398, 2007.

[3] GERPOTT, T. J., RAMS, W., SCHINDLER, A.: Customer Retention, Loyalty, and Satisfaction in the German Mobile Cellular Telecommunications Market. Telecommunications Policy 25, pp. 249-269.

[4] KIM, D. J., FERRIN, D. L., RAO, H. R.: Trust and Satisfaction, Two Stepping Stones for Successful e-commerce Relationships: A Longitudinal Exploration. Information Systems Research, 20 (2), p. 237.257, 2009.

[5] LAI, T. L.: Service Quality and Perceived Value's Impact on Satisfaction, International and Usage of Short Message Service (SMS). Information Systems Frontiers 6(4), pp. 353-368, 2004.

[6] LIM, H., H., WANG, Y. S.: An Examination of the Determinants of Customer Loyalty in Mobile Commerce Contexts. Information and Management, 43 (3), pp. 271-282, 2006.

[7] ZEITHAML, V. A., BERRY, L. PARASURAMAN, A.: The Behavioral Consequences of Service Quality. J. of Marketing, 60 (2), pp. 31-46, 1996.

[8] DENG, Z., LU, Y., WEI, K., K., ZHANG, J. Understanding Customer Satisfaction and Loyalty: An Empirical Study of Mobile Instant Messages in China. Intern. J. of Information Management, 30, 2010, p.p. 289-300.

[9] BOLTON, R., DREW, J. H.: A Multistage Model of Customers' Assessment of Service Quality and Value, J. of Consumer Research, 17, pp. 375-384, 1991.

[10] VAlaSKOVA, M., KRIZANOVA, A.: The Passenger Satisfaction in the Regional Integrated Public Transport System, PrometTraffic and Transportation, vol. 20, No. 6, 2008, pp. 401-404, Zagreb : Fakultet prometnih znanosti, ISSN 0353-5320.

[11] OLIVER, R.: Satisfaction, a Behavioural Perspective on the Consumer, New York: McGraw-Hill, 1997.

[12] FORNELL, C., JOHNSON, M. D., ANDERSON, E. W., CHA, J., BRYANT, B. E.: The American Customer Satisfaction Index. Nature, Purpose, and Findings, J. of Marketing, 60 (7), 1996. 
[13] ZEITHAML, V. A., BINTER, M. J.: Service Marketing. New York: The McGraw-Hill Companies, 1996.

[14] COREJOVA, M., ROSTASOVA, M., CHRENKOVA, A.: Knowledge Biography - Tool for Researching the Knowledge Dynamics. Global Engineering Education Conference, 2012.

[15] KIM, H.: The Churn Analysis and Determinants of Customer Loyalty in Korean Mobile Phone. Korean Information Society Review, pp. 1-18, 2000.

[16] LEE, J., LEE, J. FREICK, L.: The Impact of Switching Costs on the Customer Satisfaction-loyalty Link: Mobile Phone Service in France. J. of Services Marketing, 15(1), pp. 35-48, 2001.

[17] JOHNAROVA, R.: Marketing of Heritage and Arts. Praha, pp. 116-117, 2008.

[18] RIMARCIK, M.: Statistics for Practice, Bratislava, p. 71, 2007.

[19] TUREL, O., SERENKO, A.: Satisfaction with Mobile Service in Canada: An Empirical Investigation, Telecommunications Policy, 30 (5-6), pp. 314-331, 2006.

[20] WANG, Y., LO, H. P.: Service Quality, Customer Satisfaction and behaviour Intentions: Evidence from China's Telecommunications Industry, 1999. 